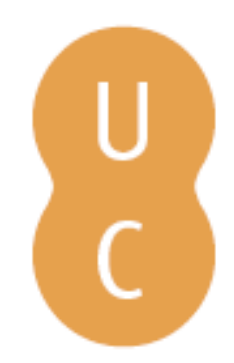

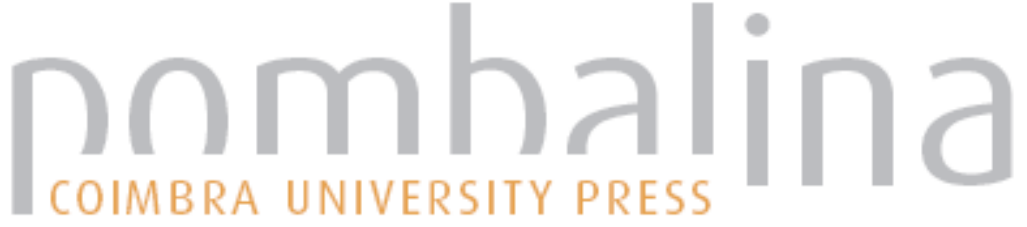

\section{Pedro Nunes e a matemática do século XVI}

Autor(es): Leitão, Henrique

Publicado por: Imprensa da Universidade de Coimbra

URL

persistente: URI:http://hdl.handle.net/10316.2/38438

DOI: $\quad$ DOI:http://dx.doi.org/10.14195/978-989-26-0764-1_2

Accessed : $\quad$ 26-Apr-2023 14:26:50

A navegação consulta e descarregamento dos títulos inseridos nas Bibliotecas Digitais UC Digitalis, UC Pombalina e UC Impactum, pressupõem a aceitação plena e sem reservas dos Termos e Condições de Uso destas Bibliotecas Digitais, disponíveis em https://digitalis.uc.pt/pt-pt/termos.

Conforme exposto nos referidos Termos e Condições de Uso, o descarregamento de títulos de acesso restrito requer uma licença válida de autorização devendo o utilizador aceder ao(s) documento(s) a partir de um endereço de IP da instituição detentora da supramencionada licença.

Ao utilizador é apenas permitido o descarregamento para uso pessoal, pelo que o emprego do(s) título(s) descarregado(s) para outro fim, designadamente comercial, carece de autorização do respetivo autor ou editor da obra.

Na medida em que todas as obras da UC Digitalis se encontram protegidas pelo Código do Direito de Autor e Direitos Conexos e demais legislação aplicável, toda a cópia, parcial ou total, deste documento, nos casos em que é legalmente admitida, deverá conter ou fazer-se acompanhar por este aviso.

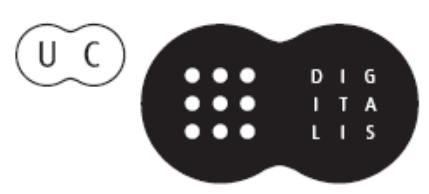


Centro Interuniversitário de História da Ciência e Tecnologia, Faculdade de Ciências, Universidade de Lisboa

leitao.henrique@gmail.com

\section{Pedro Nunes e a Matemática do Século XVI}

\section{Henrique Leitão}

\section{INTRODUÇÃO}

O objectivo deste texto consiste em fornecer alguns primeiros elementos para uma caracterização de Pedro Nunes (1502-1578) enquanto matemático do século XVI. Isto é, procura-se nestas páginas determinar de que forma Pedro Nunes se inscreveu (ou não) nas correntes intelectuais e nos temas, nas práticas e nas ocupaçôes habituais dos matemáticos do seu tempo. Como se verá, embora os traços essenciais da matemática do século XVI sejam relativamente fáceis de identificar na sua carreira e nos seus interesses, Nunes escapa a uma inscrição simples e imediata nas categorias da sua época.

Os elementos centrais da personalidade e da obra científica de Pedro Nunes foram determinados pelas tendências gerais da ciência e matemática do século XVI, e pelos condicionalismos locais específicos que afectaram a sua actividade em Portugal. Por um lado, as tendências científicas gerais definem, em grande medi$\mathrm{da}$, as principais tarefas e os principais problemas científicos, atribuindo também uma certa forma às questões científicas. Por outro lado, o contexto local, as tradições nacionais, as ocupações docentes, as solicitações pontuais, as exigências dos mecenas, etc., têm uma incidência directa, e por vezes determinante, na carreira de um cientista. Como é evidente, uns e outros factores não são independentes. ${ }^{1}$ A sua interacção gerou em Pedro Nunes um certo tipo de perfil matemático que, embora com muitos elementos típicos do século XVI, apresenta alguns interessantes traços distintivos, necessitando por isso de uma caracterização específica.

\footnotetext{
${ }^{1}$ Naturalmente, a estes dois tipos de factores - os mais gerais, próprios do tempo, e os de incidência mais local - faltaria ainda adicionar elementos de ordem estritamente pessoal (gostos e características específicas do próprio cientista, etc.), ou seja, elementos que manifestam a irredutibilidade do humano aos fatores externos, mas que são muito difíceis de aceder historicamente.
} 


\section{A Produção Noniana}

Relembremos, muito brevemente, qual foi a produção matemática de Pedro Nunes. ${ }^{2}$ Como já foi algumas vezes notado, ele não foi nem um autor precoce (o seu primeiro livro impresso foi publicado quando tinha já 35 anos), nem um autor prolífico (se exceptuarmos reedições e opúsculos menores, publicou apenas cinco obras). Em 1537 deu aos prelos em Lisboa, nas oficinas de Germão Galharde, uma colectânea de textos habitualmente referenciada pelo título genérico de Tratado da Sphera. A obra é muito desigual, contendo três traduções e dois trabalhos originais: a tradução de um texto muito elementar, o Tractatus de sphaera de João de Sacrobosco; a tradução dos primeiros capítulos (relativos ao Sol e à Lua) das Theorice nove planetarum (Novas Teóricas dos Planetas) de Jorge Purbáquio (Georg Peurbach), uma obra de astronomia teórica de nível técnico intermédio; e a tradução do livro primeiro da famosa Geografia de Cláudio Ptolomeu, um texto da maior importância na história da cosmografia e da cartografia. ${ }^{3}$ Ao lado destas traduções, Pedro Nunes apresentou dois trabalhos originais sobre questôes náuticas, respectivamente, o "Tratado sobre certas dúvidas da navegação", e o "Tratado em defensão da carta de marear», de grande novidade e valor científico e que inauguram o tratamento dos assuntos de náutica por métodos matemáticos. ${ }^{4}$

A intenção didáctica das traduções parece evidente, e o âmbito da sua utilização era muito possivelmente a educação na corte de nobres e fidalgos que, pouco hábeis na língua latina, precisavam de adquirir alguns conhecimentos técnico-científicos. Os dois tratados de náutica têm, contudo, um objectivo e um conteúdo muito diferente. Não são textos introdutórios, susceptíveis de serem lidos por pessoas com poucos conhecimentos técnicos, e também não se podem considerar textos com utilidade para os práticos do mar ou virados para o melhoramento da eficácia das navegaçôes. São cuidadosas reflexões sobre os fundamentos da navegação que então se praticava, sobre os seus pressupostos, os seus problemas e os seus métodos. Nunes submete as ideias, os procedimentos e os instrumentos náuticos a uma inspecção matemática e introduz uma distinção que explorará durante toda a sua carreira, esclarecendo que há dois modos de navegar - "per arte e per rezão" - e que a ele lhe interessa sobretudo o segundo modo, o navegar por razão, isto é, a navegação considerada como uma disciplina matemática.

$\mathrm{Na}$ altura em que se imprimia o Tratado da Sphera, Pedro Nunes tinha já mais obras, redigidas algumas em português e outras em latim, sobre matemática e cosmografia. Por indicações dispersas é possível saber quais eram alguns desses trabalhos, merecendo referência especial dois deles: um tratado sobre triângulos esféricos que

${ }^{2} \mathrm{~A}$ publicação moderna das obras de Pedro Nunes foi recentemente completada, numa edição com tradução dos originais latinos e abundantes notas explicativas promovida pela Academia de Ciências e pela Fundação Calouste Gulbenkian: Pedro Nunes. Obras, 7 vols. (Lisboa: Academia das Ciências de Lisboa, Fundação Calouste Gulbenkian, 2002-2012). Utilizaremos esta edição, designada abreviadamente como Pedro Nunes. Obras.

${ }^{3}$ Ver Pedro Nunes. Obras, vol. I, respectivamente: «Tratado da Sphera», pp. 7-45; «Theorica do Sol e da Lua tirada de latim em lingoagem per ho Doctor Pero Nunez», pp. 47-62; «Livro primeiro da Geographia de Ptolomeu», pp. 63-104. Pedro Nunes acrescentou algumas anotações às traduçōes.

${ }^{4}$ São, respectivamente: «Tratado que ho doutor Pero nunez fez sobre certas duuidas da nauegação: dirigido a el Rey nosso senhor», in Pedro Nunes. Obras, vol. I, pp. 105-119; "Tratado que ho doutor Pero nunez Cosmographo del Rey nosso senhor fez em defensam da carta de marear: com o regimento da altura. Dirigido ao muyto escrarecido: e muyto excelente Principe ho Iffante dom Luys», in Pedro Nunes. Obras, vol. I, pp. 120-174. 
preparou no início dos anos trinta e que certamente circulou em manuscrito, mas que acabou por se perder, e a tradução do De architectura de Vitrúvio, de que também não há hoje registo. ${ }^{5}$

Em 1542 foi publicado o De crepusculis, um pequeno livro de grande valor, muitas vezes considerado o mais brilhante contributo de Pedro Nunes, e que viria a ter imensa repercussão pela Europa. ${ }^{6}$ Enquanto a obra anterior, escrita em português, não tinha mais ambição do que ser lida pelos seus conterrâneos, este trabalho visava horizontes muito mais amplos, dirigindo-se ao auditório dos matemáticos europeus. O De crepusculis revela um matemático de primeira linha, com total domínio das técnicas da astronomia matemática e centrado no estabelecimento de resultados astronómicos, demonstrados rigorosamente e encadeados de um modo lógico. ${ }^{7}$ No final do seu livro Pedro Nunes incluiu ainda a versão latina do Liber de crepusculis do árabe Ibn Muª̄dh - na altura e até anos recentes atribuído a Ibn al-Haitham (Alhacen) - que foi a primeira edição impressa desse importante texto. ${ }^{8}$

Poucos anos depois, em 1546, publicou o De erratis Orontii Finaei, uma obra que, em certo sentido, é um desvio aos seus interesses principais, mas de grande importância para o historiador pois revela a competência de Nunes em tópicos matemáticos não tratados nas suas outras obras. ${ }^{9}$ Com o propósito de corrigir os erros cometidos pelo então célebre professor de matemática do Colégio Real em Paris, Orôncio Fineu (1494-1555), ao afirmar ter resolvido alguns dos problemas clássicos da geometria (em especial a duplicação do cubo e quadratura do círculo), o livro tem também desvios para analisar aspectos da teoria de proporçóes, resultados arquimedianos, relógios de Sol, propostas para determinar a longitude a partir do movimento da Lua, etc.

Após um longo hiato de duas décadas surgiu finalmente, em 1566, dos prelos de uma das mais reputadas casas impressoras da Europa, a oficina de Heinrich Petri, em Basileia, as Petri Nonii Salaciensis Opera (Obras de Pedro Nunes Salaciense). ${ }^{10}$ Tratava-se de uma obra ambiciosa, na qual o autor reunira o mais importante das suas contribuiçóes, desenvolvendo

\footnotetext{
${ }^{5}$ Sobre as obras de Pedro Nunes que não chegaram até nós, ver: Henrique Leitão, "Sobre as "obras perdidas" de Pedro Nunes", em: Pedro Nunes, 1502-1578: Novas terras, novos mares e o que mays he: novo ceo e novas estrellas. Catálogo bibliográfico sobre Pedro Nunes (Lisboa: Biblioteca Nacional, 2002), pp. 45-66.

${ }^{6}$ Pedro Nunes. Obras, vol. II, pp. 3-120 (texto latino), pp. 139-260 (tradução portuguesa).

${ }^{7}$ Analisando o processo pelo qual Nunes obteve a solução para o célebre problema do crepúsculo mínimo e a história subsequente desse problema, um dos mais destacados historadores de ciência da actualidade resumiu, em palavras que vale a pena transcrever: "While Bernoulli, l'Hospital, d'Alembert gave only an indirect, uncomplete solution of the problem, Nunes solved it completely. This solution deserves not to be forgotten", Eberhard Knobloch, "Nunes' Book on twilights», in: Luís Trabucho de Campos, Henrique Leitão, e João Filipe Queiró (eds.), International Conference Petri Nonii Salaciensis Opera Proceedings (Lisboa: Departamento de Matemática da Faculdade de Ciências da Universidade de Lisboa, 2003), pp. 113-140.

${ }^{8}$ Pedro Nunes. Obras, vol. II, pp. 123-136 (texto latino), pp. 263-276 (tradução portuguesa). O Liber de crepusculis, ou Liber de causis crepusculorum, um breve texto de origem árabe sobre refração atmosférica e os crepúsculos, com ampla circulação numa versão latina medieval, foi sempre atribuído a Alhacen até 1967 quando o historiador A. I. Sabra provou de forma incontroversa que o seu autor fora o árabe Abu ${ }^{\mathrm{c} A b d}$ Allah Muhammad ibn $\mathrm{Mu}^{\mathrm{c}}$ adh al-Jayyani, conhecido habitualmente apenas por Ibn $\mathrm{Mu}^{\mathrm{c}} \mathrm{adh}$. Este é hoje em dia o parecer consensual dos historiadores de ciência. Vide A. I. Sabra, «The authorship of the Liber de crepusculis, an $11^{\text {th }}$-century work on atmospheric refraction", Isis, 58 (1967) 77-85.
}

${ }^{9}$ Pedro Nunes. Obras, vol. III, pp. 1-122 (texto latino), pp. 127-246 (tradução portuguesa).

${ }^{10}$ Pedro Nunes. Obras, vol. IV, pp. 3-248 (texto latino), pp. 251-514 (tradução portuguesa). 
algumas das suas ideias antigas e apresentando resultados novos. A publicação numa das mais afamadas casas tipográficas da Europa (até então, recorrera apenas a impressores do seu próprio país, Germão Galharde, Luís Rodrigues, João Álvares e João da Barreira), revela não apenas a ambição do autor, mas também o estatuto internacional de que então já desfrutava. Infelizmente, composto à distância de Pedro Nunes, fora da sua vigilância e controle, o livro acabou por sair com muitos problemas tipográficos. ${ }^{11}$

As Opera contêm textos e estudos relacionados com diferentes assuntos náuticos - a análise matemática dos regimentos, das técnicas, parâmetros e instrumentos habitualmente usados pelos homens do mar - mas destacam-se acima de tudo os capítulos dedicados ao estabelecimento das propriedades matemáticas da "linha de rumo" (curva loxodrómica), capítulos que estariam na base dos importantes trabalhos matemáticos sobre essa curva e dos progressos notáveis em cartografia na segunda metade do século XVI. Nunes manuseia com grande sofisticação técnica e originalidade conceptual as técnicas de trigonometria esférica, tentando, sempre que possível, fornecer uma estrutura lógica de tipo dedutivo-euclidiano às suas teorias matemáticas. ${ }^{12}$ Mas o livro trata mais assuntos. Tem também um importante comentário - estruturado num conjunto de cinco teoremas e respectivas demonstrações - ao problema mecânico do barco a remos (In Problema mechanicum Aristotelis de motu nauigii ex remis), a mais significativa incursão de Nunes por assuntos de mecânica teórica, apresentado precisamente na altura em que as Mechanicae quaestiones (pseudo-) aristotélicas ganhavam redobrada importância na Europa. ${ }^{13}$ Tem também umas Anotaçôes às Teóricas dos Planetas de Jorge Purbáquio [In Theoricas Planetarum Georgii Purbachii Annotationes] habitualmente consideradas, juntamente com as de Erasmo Reinhold, como as mais interessantes entre as muitas que se redigiram no século XVI. ${ }^{14}$ Essas anotações são estritamente matemáticas e desprovidas de quaisquer considerações físicas ou cosmológicas; a sua elegância e rigor matemático levaram Jean Baptiste Delambre a considerar Nunes, entre todos os comentadores de Purbáquio "celui qui était le plus géomètre et le plus soigneux [...] aussi le plus instructif". ${ }^{15}$

\footnotetext{
${ }^{11}$ Como disse o impressor que, anos mais tarde, em 1573, reeditou a obra numa versão corrigida: "Faltavam não poucas coisas, outras tinham sido atrevidamente substituídas, tudo de tal forma desfigurado que o próprio autor não reconheceria o seu parto, mas antes, indignado por justa dor, difamaria e enjeitaria o livro que fervilhava de erros por todas as partes", dedicatória de António Mariz ao rei D. Sebastiāo, datada de 12 de agosto de 1573. Vide Pedro Nunes. Obras, vol. IV, p. 255.

${ }^{12}$ Os cálculos realizados no estudo da "linha de rumo" (cálculos que, por exemplo, Simon Stevin não compreendeu completamente) foram analisados em grande detalhe em diversos trabalhos de Raymond D'Hollander. Veja-se especialmente: Raymond D'Hollander, Loxodromie et Projection de Mercator (Paris, Monaco: Institut Océanographique, 2005).

${ }^{13}$ Vide Pedro Nunes. Obras, vol. IV, pp. 239-248 (texto latino), pp. 504-514 (tradução portuguesa). Vejam-se também os estudos: Henrique de Sousa Leitão, O Comentário de Pedro Nunes à Navegação a Remos, (Lisboa: Ediçōes Culturais da Marinha, 2002), e Henrique Leitão, «Pedro Nunes and the Aristotelian Mechanical Problems», in: Luís Trabucho de Campos, Henrique Leitão, João Filipe Queiró (eds.), International Conference Petri Nonii Salaciensis Opera Proceedings (Lisboa: Departamento de Matemática da Faculdade de Ciências da Universidade de Lisboa, 2003), pp. 141-182.

${ }^{14}$ Vide Pedro Nunes. Obras, vol. v, pp. 3-140 (texto latino), pp. 143-294 (tradução portuguesa). No juízo de C. Doris Hellman e Noel Swerdlow, entre os vários comentários que se redigiram às Theoricae novae planetarum de Georg Peurbach, "the most interesting are those by Reinhold and Nuñez", Dictionary of Scientific Biography (New York: Scribner, 1970-1980), vol. 15, p. 479.

${ }^{15}$ Jean-Baptiste Delambre, Histoire de l'Astronomie du Moyen Âge (Paris: Courcier, 1819), na p. 280. As pp. 274-281 são dedicadas ao estudo das Annotationes de Nunes, mas em vários outros passos ao longo da obra Delambre refere-se a cálculos e explicações do matemático português.
} 
Um ano depois Pedro Nunes publicava em Antuérpia o Libro de algebra en arithmetica y geometria (1567) uma obra que ocuparia um lugar de destaque na álgebra quinhentista. ${ }^{16}$ As publicações subsequentes de Pedro Nunes, em 1571/3, e, já depois da sua morte, em 1592, são republicações de trabalhos anteriores que têm sobretudo o interesse de revelar quais eram, na óptica do próprio autor, os seus trabalhos mais importantes, e os que foram mais procurados pelos leitores do século XVI.

As obras de Pedro Nunes tiveram uma grande divulgação causando forte impacto em alguns círculos matemáticos da Europa, muito especialmente em Espanha, França, Inglaterra e Países Baixos. ${ }^{17}$ Essas obras são os elementos mais importantes para a reconstituição do seu perfil intelectual mas estão longe de traduzir a totalidade dos interesses e das suas actividades científico-matemáticas, já que ao longo da sua vida se envolveu em outras actividades que não deixaram expressão em textos escritos.

Os passos fundamentais da sua carreira são relativamente bem conhecidos: $:^{18}$ a sua formação universitária foi em Medicina, primeiro em Salamanca, tendo depois obtido o doutoramento na Universidade de Lisboa, em 1532. A sua ligação à corte, sempre muito estreita, data dos anos vinte, quando começou a dar aulas aos irmãos mais novos do rei D. João III e outros jovens nobres, encargo que ocupou aparentemente até meados dos anos trinta. Em 1529 foi nomeado cosmógrafo, e em 1547 cosmógrafo-mor do reino. Nos anos anteriores à obtenção do doutoramento havia leccionado esporadicamente na Universidade de Lisboa, mas só em 1544, com a sua nomeação como professor de matemática na Universidade de Coimbra, se pode verdadeiramente dizer que passou a ter uma carreira como docente, que terminaria com a sua jubilação em 1564.

Da sua produção impressa, que se pode concluir quanto aos temas? Em primeiro lugar, naturalmente, a importância central que tiveram os trabalhos sobre náutica e navegação teórica no desenvolvimento da sua carreira, mas num sentido que adiante importará precisar melhor. Sob esta designação agrupam-se temas diversos que vão desde os importantes estudos em torno da "linha de rumo" e suas propriedades, às discussões sobre as propriedades matemáticas das cartas náuticas, a concepção de instrumentos, a inspecção dos princípios matemáticos dos regimentos náuticos, a abordagem matemática à cosmografia, etc. Há também a assinalar importantes trabalhos sobre astronomia teórica, disciplina que, aliás, forneceu as técnicas matemáticas e os métodos que Nunes usou nos seus trabalhos sobre questôes náuticas.

\footnotetext{
${ }^{16}$ Vide Pedro Nunes. Obras, vol. vi. No julgamento de Henri Bosmans: "l'Algèbre de Nuñez est à tout point de vue remarquable", os seus procedimentos são "d'une exactitude bien rare alors", e "aucun contemporain ne le surpasse en rigueur, Maurolyco seul l'atteint par l'abstraction et la généralité du raisonnement, par l'élégance et l'heureux choix de l'algorithme", concluindo: "Parmi les grands mathématiciens qui séparent Stifel et Cardan, de Viète, il brille au tout premier rang". H. Bosmans, "L'Algèbre de Pedro Nuñez», Annaes Scientificos da Academia Polytechnica do Porto, 3 (1908) 222-271.

${ }^{17}$ Sobre a divulgação e o impacto das obras de Pedro Nunes na Europa, em finais do século XVI e durante o século XVII, ver: Henrique Leitão, «Sobre a difusão europeia da obra de Pedro Nunes», Oceanos, 49 (2002) 110-128, e Bruno José M. G. Pereira de Almeida, A Influência da Obra de Pedro Nunes na Náutica dos Séculos XVI e XVII: Um Estudo de Transmissão de Conhecimento, Dissertação de doutoramento (Lisboa: Universidade de Lisboa, 2011).

${ }^{18}$ Henrique Leitão, "Para uma biografia de Pedro Nunes: O surgimento de um matemático, 1502-1542», Cadernos de Estudos Sefarditas, 3 (2003) 45-82; Fernando Taveira da Fonseca, «Pedro Nunes na Universidade. I Lisboa", in: Estudos em Homenagem a Luís António de Oliveira Ramos (Porto: Faculdade de Letras da Universidade do Porto, 2004), vol. 2, pp. 537-544.
} 
De notar que os seus textos não dão quaisquer indicações de ter feito trabalho numérico associado à astronomia (preparação de tabelas, etc.), nem de qualquer interesse por astrologia ou por especulações físico-filosóficas sobre a estrutura cosmológica do mundo. Mas há também discussões sobre questões euclidianas e arquimedianas, textos sobre mecânica teórica, questôes de óptica relacionadas com a astronomia, etc. Também não pode ser esquecido, o seu importante contributo em álgebra. Tematicamente, portanto, o leque é amplo: astronomia matemática e temas correlatos, geografia teórica, cartografia matemática, cosmografia e temas De Sphera; náutica teórica, instrumentação, óptica astronómica, trigonometria esférica, mecânica teórica; álgebra; geometria euclidiana, etc.

\section{Pedro Nunes e matemática do Século XVI}

Os historiadores têm sublinhado, como uma característica típica da matemática do século XVI, a grande diversidade de funções e cargos em que os matemáticos exerceram as suas actividades. ${ }^{19}$ Dois dos contextos onde estas actividades foram exercidas - na corte e na universidade - têm as suas origens na Idade Média e neles cultivavam-se sobretudo saberes e práticas ligadas à astronomia ou astrologia. O terceiro âmbito para as actividades matemáticas é típico do séc. XVI e era exterior à corte e à universidade. Estava ligado a um certo tipo de cultura e actividade mais prática e tem sido identificado sobretudo pela designação proposta por Eva Taylor de "mathematical practitioner", ou praticante matemático. ${ }^{20}$

Uma outra forma de descrever o amplo leque em que se abriam as actividades dos matemáticos quinhentistas seria olhando para a sua estratificação social. Esta começava no nível mais baixo do "matemático-artesão", um homem que resolvia problemas práticos empregando alguns processos numéricos (calculava o volume de pipas, estabelecia calendários, ensinava aritmética comercial, etc.) e, em geral, ganhava a vida impressionando clientes e público com a sua destreza no manejo dos números, e indo até o "matemático-humanista", geralmente um universitário de fortes interesses pela filologia clássica, muitas vezes ocupado na recuperação textual de obras científicas do passado. Pelo meio haveria a considerar várias outras variantes, como matemáticos ligados ao fabrico de instrumentos, ou matemáticos que agiam como consultores de assuntos técnicos, militares ou astrológicos.

${ }^{19}$ Ver a coletânea de trabalhos em: Irmgard Hantsche (Hrsg.), Der "mathematicus": Zur Entwicklung und Bedeutung einer neuen Berufsgruppe in der Zeit Gerhard Mercators (Bochum: Brockmeyer, 1996), especialmente: Rienk Vermij, «Mathematics at Leiden: Stevin, Snellius, Scaliger», pp. 75-92, e Stephen Johnston, "The identity of the mathematical practitioner in $16^{\text {th }}$-century England», pp. 93-120. E ainda: Robert S. Westman, "The Astronomer's Role in the Sixteenth Century: A Preliminary Study», History of Science, 18 (1980) 105-147; Mordechai Feingold, The Mathematicians' Apprenticeship: Science, Universities and Society in England, 1560-1640 (Cambridge: Cambridge University Press, 1984); Mario Biagioli, «The Social Status of Italian Mathematicians, 1450-1600", History of Science, 27 (1989) 41-95; Nicholas Jardine, "The Places of Astronomy in Early-Modern Culture», Journal for the History of Astronomy, 29 (1998) pp. 49-62.

${ }^{20}$ Ver o trabalho fundamental de E. G. R. Taylor, The Mathematical Practitioners of Tudor and Stuart England (Cambridge: Cambridge University Press, 1954). Ver ainda: Stephen Johnston, «Mathematical practitioners and instruments in Elizabethan England», Annals of Science, 48 (1991) 319-344. 
Os interesses de Pedro Nunes foram sobretudo teóricos, mas em assuntos de matemática aplicada, naquilo que na altura se designava por "matemática mista". ${ }^{21}$ É certo que propôs alguns instrumentos, mas essas propostas têm muito mais interesse como concepções teóricas do que como instrumentos reais. Além disso, ele nunca teve interesse directamente ligado à construção de quaisquer artefactos (instrumentos, globos ou mapas), afastando-se, por isso, do perfil de alguns seus eminentes contemporâneos, como Gemma Frisius ou Pedro Apiano, que, apesar de tudo, apresentam importantes semelhanças com ele. Por obrigação dos cargos que ocupou, Nunes teve de interagir de perto com o mundo da artesania técnica, mas ele próprio não se envolveu nessas actividades e por isso não caberia na classificação de "mathematical practitioner". Em particular, nunca foi um cartógrafo e o seu envolvimento na produção directa de cartas parece não ter passado dos conselhos e instruções que transmitiu aos cartógrafos. O seu perfil científico é, deste ponto de vista, muito diverso do de Gerard Mercator.

Até mesmo no que diz respeito à astronomia, assunto em que se envolveu de maneira especialmente intensa, a sua atitude teve algumas particularidades. Embora tenha manifestado sempre o interesse pela aplicação das técnicas e procedimentos da astronomia teórica a outras disciplinas (a cosmografia e a navegação, sobretudo) nunca parece ter-se dedicado com muito afinco às observações astronómicas nem ao esforço - muito importante no século XVI - de melhoria da precisão dos instrumentos astronómicos.

Mas se os seus interesses não eram os do homem prático, também não foi seduzido por especulações muito abstractas. Com a excepção de alguns tópicos tratados no De erratis Orontii Finaei - as discussōes em torno do livro V de Euclides, por exemplo - Pedro Nunes não se dedicou muito aos aspectos mais abstractos da matemática do seu tempo: não entrou em questōes metodológicas acerca da certeza da matemática e só se interessou tangencialmente por teoria de proporções. Manifestou interesse por alguns dos problemas mais delicados da astronomia teórica (por exemplo, o problema do chamado movimento de trepidação) mas sobretudo na medida em que esses assuntos tinham reflexo a nível mais aplicado. Pela mesma ordem de razōes estão completamente ausentes dos seus livros quaisquer desvios de tipo filosófico, cosmológico e até mesmo físico, no sentido de filosofia natural. Nunes foi sempre um matemático.

O que foi constante em Pedro Nunes foi o seu desejo de analisar matematicamente fenómenos ou objectos reais. Não porque estivesse de maneira especial interessado em obter resultados de directa aplicação prática, mas porque os fenómenos da natureza ou da técnica lhe sugeriam problemas matemáticos de interesse. Isto é: o ponto de partida para as suas investigações matemáticas foi quase sempre a natureza, mas foi de investigaçōes matemáticas que se ocupou sempre, sem mostrar muito desejo de "regressar" ao mundo natural.

Nunes desempenhou também um papel significativo no que diz respeito à edição de textos científicos. Desde logo, pelas traduções que levou a cabo, muito em especial a tradução do Livro I da Geografia de Ptolomeu e a (perdida) do De architectura de Vitrúvio. Mas também pela edição da versão latina do Liber de crepusculis de Ibn Mucādh

${ }^{21}$ Richard D. McKirahan Jr., "Aristotle’s Subordinate Sciences», British Journal for the History of Science, 11 (1978) 197-220; Gary I. Brown, "The evolution of the term 'Mixed Mathematics', Journal of the History of Ideas, 52 (1991) 81-102; Peter Dear, "Mixed Mathematics», in: Peter Harrison, Ronald L. Numbers and Michael H. Shank (eds.), Wrestling With Nature. From Omens to Science (Chicago and London: The University of Chicago Press, 2011), pp. 149-172. 
e pela primorosa apresentação da proposição III do De mensura circuli de Arquimedes no cap. XI do De erratis Orontii Finaei. ${ }^{22}$ Este aspecto da sua carreira, que o aproxima mais da figura do "matemático-humanista" tem sido poucas vezes notado e merece um desenvolvimento explicativo.

Uma característica saliente da matemática renascentista foi o esforço de recuperação das tradições matemáticas da antiguidade. O importante movimento de tradução científica dos séculos XI a XIII havia trazido ao mundo latino um manancial enorme de textos científicos antigos, mas a despeito do seu imenso mérito apresentava limitaçôes evidentes. Para além dos problemas linguísticos, muitas dessas traduções revelavam uma falta de compreensão do conteúdo científico. A partir do séc. XV, sob o influxo do interesse humanista pelos textos clássicos, os critérios linguísticos e editoriais tornaram-se muito mais exigentes e passou a impor-se uma recuperação total dos textos da ciência antiga e não a sua mera tradução. Este movimento de recuperação científica marcou de modo mais determinante três âmbitos matemáticos: as tradições mecânicas de Arquimedes, Herão, Papo e da Mechanica aristotélica; a tradição geométrica na longa linha desde Euclides, Apolónio, Papo e Proclo; a tradição astronómica helenista, sobretudo em torno dos trabalhos de Ptolomeu, mas também com as técnicas matemáticas de Teodósio e Menelau.

$\mathrm{O}$ mais profundo e complexo movimento de recuperação textual e científica ocorreu com as obras de Arquimedes. A importância deste fenómeno foi de tal ordem que, nas palavras de Alexandre Koyré, quase se poderia "resumir o trabalho científico do século XVI pela recepção e pela compreensão gradual da obra de Arquimedes". ${ }^{23}$ Conhecido de uma forma apenas fragmentária durante a Idade Média, a recuperação das obras de Arquimedes foi uma das conquistas mais importantes da matemática do século XVI. No início do século pouco mais se sabia dos trabalhos de Arquimedes para além do que podia ler na enciclopédia de Giorgio Valla, De expetendis et fugiendis rebus (Veneza, 1501), e na edição, publicada em 1503, por Luca Gaurico, com as traduções medievais de William de Moerbecke. Foi preciso o transcurso de quatro décadas para finalmente aparecer, em 1543, uma edição veneziana da responsabilidade de Niccolò Tartaglia (que incluía, além das obras anteriormente publicadas por Gaurico, a tradução de Moerbecke dos dois livros De planorum aequilibris e o livro I do De corporibus fluitantibus). Mas o ponto de viragem na divulgação do corpus arquimediano foi o aparecimento da famosa edição das Opera de Arquimedes, promovida por Thomas Geschauf em 1544 (Basileia, J. Herwagen), com texto grego e uma tradução de Jacob de Cremona, e os comentários de Eutócio. ${ }^{24} \mathrm{Na}$ segunda metade da

\footnotetext{
${ }^{22}$ Vid. Pedro Nunes. Obras, vol. III, pp. 54-63.
}

${ }^{23}$ Alexandre Koyré, Estudos Galilaicos (Lisboa: Dom Quixote, 1986), p. 15. É a tradução portuguesa de Études Galiléennes (Paris: Hermann, 1966). O parecer de Koyré foi confirmado por outros historiadores, por exemplo no caso italiano: "Ogni esame delle scienze matematiche in Italia nella seconda metà del Cinquecento porta a concludere che una connoscenza crescente e più precisa delle Opere di Archimede fu un fattore decisivo dé sviluppo", Ugo Baldini, "Archimede nel seicento italiano", in: Archimede. Mito, Tradizione, Scienza, a cura di Corrado Dollo (Firenze: Leo S. Olschki, 1992), pp. 237-289.

${ }^{24}$ Archimedis ... Opera, quae quidem extant ... et graece et latine ... edita. Adjecta sunt Eutocii ... Commentaria ... Basileia, 1544. Texto grego com tradução latina de Jacobus Cremonensis, de cerca 1450. Esta edição contém os dois livros De sphaera et cylindro, De mensura circuli, De conoidibus et sphaeroidibus, De lineis spiralibus, os dois livros De planorum aequilibris, o Arenarius, e o Quadratura parabolae. Tem ainda os comentários de Eutócio (ao De sphaera et cylindro ao De mensura circuli e ao De planorum aequilibris). 
centúria este esforço continuaria, com o aparecimento das importantes edições de Federico Commandino, Tartaglia e Guido Ubaldo. ${ }^{25}$

Pedro Nunes não foi alheio a este importante movimento intelectual; aliás, inscreveu-se nele de maneira significativa, se bem que apenas pontual. No De erratis Orontii Finaei, corrigindo uma explicação errónea do matemático francês a propósito do $D e$ mensura circuli, explicou de maneira rigorosa a técnica usada por Arquimedes para estimar a razão entre uma circunferência e o seu diâmetro. No dizer do historiador Marshall Clagett: "Nunes not only corrected the errors of the French mathematician but revealed himself as the most penetrating student of Archimedes' technique of approximations yet to write in Latin." 26

A par de uma participação assinalável na recuperação do legado arquimediano, Pedro Nunes teve também um lugar de relevo na tratadística de astronomia teórica, outro dos campos de importante desenvolvimento textual (e científico) no século XVI. A partir do século XV, começara a ganhar corpo a ideia de que se impunha uma "reforma" na astronomia, que passava, entre outros aspectos, pela recuperação e estudo de grandes textos do passado e pela produção de textos de astronomia mais rigorosos e claros. Jorge Purbáquio e João Regiomontano foram os principais impulsionadores deste movimento e a eles se devem alguns dos mais importantes textos de cariz técnico, que influenciaram decisivamente o renovamento dos estudos astronómicos. Purbáquio redigiu as muito influentes Theorica nove planetarum, e Regiomontano (a partir de uns capítulos iniciais preparados por Purbáquio), o Epitome do Almagesto, uma obra que iria alterar radicalmente a investigação em torno dos modelos e técnicas da astronomia teórica. ${ }^{27} \mathrm{~A}$ par do aparecimento destes novos textos, no século XVI assistir-se-ia ainda ao aparecimento de várias ediçóes do Almagesto de Ptolomeu: impresso pela primeira vez em 1515 (Veneza, Petrus Liechtenstein) na tradução latina de Gerardo de Cremona, a partir do árabe; pouco depois foi publicada a tradução latina, a partir do grego, de Jorge de Trebizonda (Veneza, Giunta, 1528) e, finalmente, em 1538, a editio princeps do texto grego (Basileia, J. Walderus). O desenvolvimento

${ }^{25}$ Em 1558 Commandino publicou uma tradução dos trabalhos de Arquimedes que incluia o Circuli dimensio, De lineis spiralibus, Quadratura parabolae, De conoidibus et spheroidibus, e o Arenarius (Veneza, P. Manuntius). Commandino editou a tradução de Moerbecke do De corporibus fluitantibus, introduzindo correções, em 1565 (Bolonha: A. Benacci). No mesmo ano Tartaglia também editou a pouco correta tradução de Moerbecke do De corporibus fluitantibus, em Veneza, e Guido Ubaldo del Monte publicou em 1588 o In duos Archimedis aequeponderantium libros paraphrasis (Pesaro H. Concordia).

${ }^{26}$ Marshall Clagett, Archimedes in the Middle Ages. 10 vols. em 5 partes. No volume Three. The Fate of the Medieval Archimedes 1300-1565. Part III: The Medieval Archimedes in the Renaissance, 1450-1565 (Philadelphia: The American Philosophical Society, 1978), p. 1246. Noutro passo, Clagett explica: "I must also underline the fact that in Nunes' criticism of Finés first method [...] he revealed himself as the first Western author (except perhaps Regiomontanus) to understand or, at least, to explain the nuances of Archimedes' use of approximations which had eluded Fibonacci, Pacioli and Finé, all of whom had fashioned caricatures of the Archimedean proof. Consequently, Nunes deserves an honored place among the students of Archimedean mathematics in the first half of the sixteenth century", Clagett, Archimedes in the Middle Ages, p. 1222.

${ }^{27}$ Sobre a obra de Peurbach veja-se: E. J. Aiton, «Peurbach's Theoricae novae planetarum. A translation with commentary», Osiris, $2^{\text {nd }}$ series, 3 (1987) 5-44. Para a biografia e os contributos científicos de Regiomontano continua indispensável o estudo de Ernst Zinner, Regiomontanus: His Life and Work, translated by Ezra Brown (Amsterdam: North Holland, 1990), pp. 96-97, 219-220. [Originalmente: Leben und Wirken des Joh. Müller von Königsberg gennant Regiomontanus, 2. a ed. (Osnabrück: Otto Zeller, 1968)]. 
da astronomia no século XVI esteve em grande medida ligado à produção de textos com o objectivo de esclarecer e comentar o Almagesto.

Os progressos em astronomia teórica tiveram repercussões em outras áreas. A necessidade de desenvolver métodos simultaneamente mais rigorosos e mais expeditos para efectuar os cálculos astronómicos e permitir a produção de tabelas cada vez mais ambiciosas levou a importantes melhoramentos em trigonometria plana e esférica, e ao aparecimento na Europa latina dos primeiros tratados matemáticos consagrados ao tema. Pedro Nunes foi profundamente influenciado por este movimento intelectual. Como já referimos, um dos seus primeiros trabalhos, hoje perdido, foi precisamente um tratado sobre trigonometria esférica. É o próprio que nos diz, com uma ponta de vaidade, que o seu tratado fora escrito antes que conhecesse os textos sobre triângulos esféricos de Regiomontano e de Jabir ibn Afflah, e que não era inferior a esses: "escreui a geometria dos triangulos Spheræs largamente antes que de Alemanha nos mandassem a Espanha os liuros de Gebre e Monteregio que na mesma materia falam: e despoys de lidos nam rompi o que tinha escripto" 28 .

Associada à constituição de um corpus astronómico avançado e rigoroso colocava-se uma tarefa da maior importância, a recuperação de textos da tradição árabe. Nestes casos levantavam-se muitas dificuldades já que as traduções em circulação, na maior parte dos casos traduçôes medievais, tinham muitos problemas. Pedro Nunes não foi indiferente a este assunto. Quando publicou o seu De crepusculis (1542) juntou-lhe, no final o "Liber de causis crepusculorum", então atribuído a Allacen, numa versão latina que o próprio Nunes diz ter revisto. Até essa data circularam apenas versões manuscritas desse importante texto e quando, trinta anos mais tarde surgiu a segunda edição, por Friederich Riesner, o texto era derivado do de Nunes. ${ }^{29}$ Em 1573 e 1592 a versão preparada por Nunes foi novamente publicada. Conclui-se assim, não apenas que o matemático português foi o primeiro a dar ao prelo aquela importante obra, como ainda que, durante toda a segunda metade do século XVI, as versóes impressas que hoje conhecemos eram ou as estabelecidas por Nunes, ou as derivadas do texto que ele mandara imprimir.

A astronomia teórica, com as disciplinas auxiliares - por exemplo, a trigonometria plana e esférica - e também com as extensões naturais, como a cosmografia matemática, tornou-se o eixo central do pensamento matemático de Pedro Nunes. Os astrónomos matemáticos do início do século XVI procuravam dar seguimento ao programa de Regiomontano e a conexão de Nunes com esta tradição intelectual foi muito próxima. Entre os contemporâneos, João Werner foi possivelmente o autor por quem Nunes mostrou maior admiração, citando-o com frequência e sempre em termos elogiosos, Johannes Stöffler e Johannes Schöner também aparecem com frequência nos seus

${ }^{28}$ Pedro Nunes. Obras, I, p. 68. As obras de Gebre [Jabir ibn Afflah] e Monteregio a que Pedro Nunes faz alusão são o Gebri Filii Affla Hispalensis. De Astronomia libri IX que vem incluído no Instrumento primi mobilis (Nuremberga, 1534) de Pedro Apiano, e o célebre De triangulis omnimodis libri V (Nuremberga, 1533), de Regiomontano. Volta a referir-se a esse estudo, em que escrevera "largamente" acerca de trigonometria esférica, no "Tratado (...) sobre certas duuidas da navegação”. Aí diz: “(...) nos triangulos de linhas curuas he da maneira que digo: como no tratado que sobre elles escreui demonstrei", e mais adiante precisa: "como demonstrey na xxiiij proposição do primeiro liuro dos triãgulos spheraes”. Pedro Nunes. Obras, I, p. 162 e p. 165

${ }^{29}$ Vide Bernard R. Goldstein, «Ibn Mucadh's treatise on Twilight and the height of the atmosphere», Archive for History of Exact Sciences, 17 (1977) 97-118. 
trabalhos. Do ponto de vista da astronomia a filiação de Nunes na tradição germânica é evidente. É também neste âmbito que se devem ler as observações breves, mas importantes, que fez ao De revolutionibus (1543) de Copérnico. ${ }^{30}$

Uma outra área de intensa actividade científica durante o século XVI em que Pedro Nunes participou activamente e com grande destaque foi a álgebra. No caso da álgebra, não se tratava tanto da recuperação de um saber antigo, mas sobretudo da necessidade de estabelecer uma base fundacional rigorosa e coerente para as regras algébricas herdadas da tradição árabe. ${ }^{31} \mathrm{~A}$ fundamentação da álgebra nos saberes da antiguidade clássica e a clarificação conceptual de muitos dos seus aspectos tornou-se uma tarefa que ocupou muitos matemáticos quinhentistas, entre os quais o próprio Pedro Nunes. $\mathrm{O}$ seu interesse profundo por questôes algébricas - assunto que o ocupou durante três décadas - mostra também que a sua personalidade matemática era muito mais ampla do que a de um mero cosmógrafo ou matemático "astrónomo".

Mas talvez o traço das ciências matemáticas do século XVI que mais influenciou Pedro Nunes e do qual ele se veio a tornar um dos protagonistas mais destacados foi o do progressivo alargamento do campo de aplicação da matemática a novas áreas e novos problemas. Extravasando os três tópicos que, desde a antiguidade, haviam constituído o âmbito essencial para o uso da matemática - a astronomia, a óptica e a música os matemáticos quinhentistas foram progressivamente empregando técnicas matemáticas para estudar uma variedade cada vez maior de fenómenos naturais. Esta tendência observa-se em muitos dos seus trabalhos, mas, naturalmente, de maneira mais preponderante nos seus textos sobre náutica onde procede a um exame mais ou menos sistemático dos conceitos, técnicas e instrumentos usados pelos homens de mar, à luz dos princípios matemáticos que lhe subjazem.

\section{Pedro Nunes e o contexto Português}

A secção anterior deixou claro que embora no que diga respeito aos temas e interesses gerais Pedro Nunes se ache claramente inscrito nas tendências principais de matemática do seu tempo, a determinação final dos assuntos em que acabou por trabalhar e as actividades matemáticas em que se envolveu, foram profundamente influenciadas pelo contexto local em que viveu, isto é, pela sua situação em Portugal no século XVI.

Ao longo da sua vida, como já assinalámos antes, Pedro Nunes desempenhou diversos cargos, que corresponderam a uma imersão em contextos sociais muito diversos. Teve uma ligação muito estreita com o poder real, tendo sido tutor de matérias científicas a príncipes e jovens nobres na corte, e consultor de questóes científicas do rei. Também por nomeação régia foi cosmógrafo (1529) e depois cosmógrafo-mor (1547)

\footnotetext{
${ }^{30}$ Entre outros aspetos, estes comentários publicados em 1566 têm o interesse de se contarem entre as primeiras referências ao livro de Copérnico num livro impresso, por um astrónomo competente. Vid. Henrique Leitão, "Uma nota sobre Pedro Nunes e Copérnico», Gazeta de Matemática, vol. 143 (2002) pp. 60 -78.

${ }^{31}$ Sobre a importância do Libro de algebra de Pedro Nunes no panorama da álgebra quinhentista, ver o recente número temático dos Quaderns d'Història de l'Enginyeria, vol. XI (2010), coordenado por Maria Rosa Massa Esteve, e ver ainda as várias contribuições na obra de Sabine Rommevaux, Maryvonne Spiesser et Maria Rosa Massa Esteve (dir.), Pluralité de l'Algèbre à la Renaissance (Paris: Honoré Champion, 2012).
} 
tendo por isso que colaborar de perto com os profissionais ligados às actividades marítimas e cabendo-lhe não apenas o exame de pilotos, cartógrafos e fabricantes de instrumentos náuticos, mas também a leccionação de aulas, o aconselhamento destes profissionais e a certificação de cartas e instrumentos. Finalmente, a partir de 1544 foi professor de matemática na Universidade de Coimbra.

Contudo, estes diferentes contextos incidiram de maneira muito diferente na sua carreira científica. Uma característica muito significativa dessa carreira, que tem sido pouco notada, é o facto de os seus contributos científicos datarem quase todos da década de trinta. Essa foi para ele uma década excepcionalmente criativa de tal modo que, em grande medida, se pode dizer que o resto da sua carreira consistiu no aprofundar e desenvolver as primeiras ideias, intuições e propostas que formulara nesses anos. Aquele que parece ter sido o seu primeiro contributo científico de nota (presumivelmente concebido logo no início dos anos trinta) foi o desenvolvimento de métodos para achar a latitude a qualquer hora do dia, isto é, sem ter que esperar pelo meio-dia. Este assunto das técnicas extrameridianas para determinar a latitude ocupá-lo-ia muito tempo nos anos seguintes. Pouco depois, em meados da década, a propósito de umas dúvidas que lhe haviam sido colocadas por Martim Afonso de Sousa, redigiu o "Tratado sobre certas dúvidas da navegação», e de seguida o "Tratado em defensão da carta de marear». Em 1537, seguramente com apoio real, viu finalmente publicados os seus primeiros textos. A publicação dos tratados de náutica envolveu-o imediatamente numa discussão com um "bacharel" que questionou alguns aspectos das suas ideias. A polémica que então se gerou é interessante não apenas pelo seu conteúdo científico (mostrando, por exemplo, que nos inícios dos anos quarenta Pedro Nunes já tinha uma concepção muito mais aperfeiçoada das propriedades matemáticas da linha de rumo do que transparece nos textos de 1537), mas também pelo que revela da dinâmica de mecenato e de apoio às actividades científicas por parte da casa real, em especial do infante D. Luís, que foi discípulo de Nunes.

Nunes estava bem consciente da natureza e da importância dos seus contributos científicos desses anos. Escrevendo no final dos anos trinta (o mais tardar em 1540), resumiu-os desta forma: "eu primeiramente nestas partes tratei a cosmografia por modos científicos e engenhosos, onde não se sabia mais que buscar um lugar em Ptolomeu e ler por Pompónio Mela. Achei como se tomasse a altura do pólo a toda hora do dia e outras coisas proveitosas para a navegação, ensinei aos excelentíssimos príncipes o Infante Dom Luís, o Infante Dom Henrique e o Infante Dom Duarte.". ${ }^{32}$

Mas não foram só as investigaçōes sobre os fundamentos matemáticos da navegação, da cartografia e da cosmografia que tiveram a sua origem nos anos trinta. Foi também nessa década que ele preparou o seu livro sobre álgebra, uma obra que estaria em repouso durante muitos anos para finalmente, já nos anos sessenta, ser muito ampliada, vertida para castelhano e, finalmente, publicada. ${ }^{33}$ Também foi nos anos trinta que

${ }^{32}$ No «manuscrito de Florença», vid. Pedro Nunes. Obras, vol. vII, p. 85. A frase faz referência às ideias e descobertas por ele desenvolvidas nos anos trinta do século XVI e depois publicadas na sua primeira obra impressa, em 1537. Tenha-se presente, em particular o texto "Como se tomara a altura do polo em todo o tempo que ouuer sol» (Pedro Nunes. Obras, vol. I, pp. 160-161).

${ }^{33}$ Sobre a origem do Libro de algebra, ver: Henrique Leitão, «Sobre as Notas de Álgebra atribuídas a Pedro Nunes (ms Évora, BP, Cod. CXIII/1-10)», Euphrosyne, 30 (2002) 407-416. 
trabalhou no problema dos crepúsculos, que enviou para a tipografia em 1541, e foi também pelo início dos anos trinta que se começou a interessar por questôes mecânicas. ${ }^{34}$

O facto de quase todos os temas científicos da carreira de Pedro Nunes terem ficado definidos na década de trinta sugere imediatamente que se olhe com atenção para o contexto social em que se desenrolava a sua vida profissional durante esses anos. Este contexto consistia essencialmente em, por um lado, uma ligação estreita à corte, que lhe dava não apenas um acesso próximo ao poder, mas que o colocava na dependência directa de um poderoso mecenas, e, por outro lado, os deveres de cosmógrafo que o obrigavam ao contacto com pilotos, cartógrafos, construtores de instrumentos, e outros homens da vida prática do mar. ${ }^{35}$

Esta peculiar combinação de funçôes pode talvez explicar algo da sua produção, em particular a curiosa ambivalência que parece adivinhar-se entre o seu pendor por actividades de matemático de corte, um intelectual de tipo humanista, ocupado sobretudo numa aproximação textual à matemática, tão em voga no século XVI, e o seu permanente interesse por problemas que tivessem origem na vida real e no contacto com a prática, muito em especial problemas relacionados com as viagens marítimas. Em alguns casos, é o próprio Nunes que declara que a origem de uma investigação esteve ligada às suas funçôes na corte: as suas reflexões sobre a linha de rumo são iniciadas por questōes colocadas por um nobre, Martim Afonso de Sousa; as suas indagaçôes sobre a duração dos crepúsculos por discussões com o príncipe D. Henrique. Mesmo que haja algo de retórico nestas atribuiçôes, não oferece dúvida que, para Pedro Nunes, a vida na corte e o contacto com os práticos do mar foi a combinação que fez disparar o seu potencial criativo.

À primeira vista dir-se-ia que a Universidade parece ter desempenhado um papel menor na estimulação intelectual de Pedro Nunes, uma vez que as suas ocupações lectivas na Universidade de Coimbra só se iniciaram a partir de 1544, já depois dos seus anos mais criativos. Na verdade, apenas as suas Anotaçôes às Teóricas dos Planetas de Jorge Purbáquio, publicadas pela primeira vez em 1566, parecem ter tido origem nas aulas de Coimbra. Mas talvez as coisas não se tenham passado exactamente assim. É muito possível que a tomada do lugar de professor de matemática em Coimbra tenha alguma relação com a publicação, em 1546, do De erratis Orontii Finaei. Pedro Nunes não obtivera o destacado lugar de professor de matemática na Universidade de Coimbra pelo percurso usual. Não concorrera directamente a esse lugar e não o disputara com ninguém. A sua nomeação fora por indicação directa do rei, o que

\footnotetext{
${ }^{34}$ Como decorre das suas próprias palavras no início do De crepusculis (Pedro Nunes. Obras, vol. II, p. 5).

${ }^{35}$ Sobre a importância das cortes europeias como locais para a produção científica, veja-se: Dario Franchini et al., La Scienza a Corte (Roma: Bulzoni, 1979); Bruce Moran, «Wilhelm IV of Hesse-Kassel: Informal Communication and the Aristocratic Context of Discovery, in Thomas Nickles (ed.), Scientific Discovery: Case Studies (Dordrechet: Reidel, 1980), pp. 67-96; Robert S. Westman, "The Astronomer's Role in the Sixteenth Century: A Preliminary Study», History of Science, 18 (1980) 105-147; Richard S. Westfall, «Science and Patronage: Galileo and the Telescope», Isis, 76 (1985) 11-30; Robert S. Westman, «Proof, Poetics and Patronage: Copernicus's Preface to De revolutionibus, in: David C. Lindberg and Robert S. Westman (eds.), Reappraisals of the Scientific Revolution (Cambridge: Cambridge University Press, 1990), pp. 167-205; Mario Biagioli, «Galileo’s System of Patronage», History of Science, 28 (1990) 42-45; Bruce Moran, (ed.), Patronage and Institutions (Rochester: Boiydell Press, 1991); Mario Biagioli, Galileo Courtier. The Practice of Science in the Culture of Absolutism (Chicago: The University of Chicago Press, 1993), há uma tradução portuguesa: Galileu Cortesão. A Prática da Ciência na Cultura do Absolutismo (Porto: Porto Editora, 2003).
} 
talvez causasse algum desagrado na universidade e teria certamente desatado algumas línguas maledicentes. Não parece muito rebuscado imaginar que ele precisasse de rapidamente deixar bem clara a sua valia e a sua competência, o que ficaria sobejamente demonstrado com a denúncia pública (e devastadora) dos erros do famoso matemático de Paris. ${ }^{36}$

Seja como for, em 1548 Nunes já era apresentado como uma das glórias da universidade de Coimbra e comparado a um Arquimedes. As palavras do rhetor João Fernandes, na oração proferida aquando da visita do infante D. Luís à universidade de Coimbra, só pecam por hiperbólicas. A antiguidade possuiu vários Arquimedes, e contudo a nossa época contentou-se com um só Pedro; é que não aparecem com frequência os diamantes, para que o seu valor esteja na raridade. Que hei de eu dizer da tua completa erudição na excelência de toda a matemática? Tudo resumirei numa palavra. É graças a ti que o nosso Príncipe D. Luís, para quem a terra é um ponto, pode contemplar os vastíssimos orbes do mundo" ${ }^{37}$.

Foram também obviamente as exigências locais que deram origem a essa interessante peculiaridade da carreira de Nunes que foi a sua atenção à produção de trabalhos em português, em especial à tradução de textos científicos latinos. Para uma mente científica criativa, a realização de traduções é sempre uma tarefa penosa. No caso de Pedro Nunes foi levada a cabo quase de certeza em cumprimento de instruçôes da corte, mas o seu desempenho como tradutor é digno de nota e mostra, mais uma vez, o seu pioneirismo. Deixe-se de lado a menos significativa das suas traduções, do Tratado da Esfera, sobre a qual nada há a apontar já que o texto, muito elementar, havia sido traduzido para português em pelo menos outras duas ocasiōes anteriores. Muito mais interessante é a tradução do livro I da Geografia de Ptolomeu - possivelmente a primeira tradução desse texto para vernáculo em toda a Europa - e a tradução dos primeiros capítulos das Novas Teóricas dos Planetas de Purbáquio, cuja actualidade fica patente notando que a primeira tradução para um vernáculo (italiano) da totalidade do texto só se deu em 1558. Acresce ainda que, em 1541, Pedro Nunes teria já pronta uma tradução portuguesa do De architectura de Vitrúvio. Esse trabalho perdeu-se e não é possível saber nada acerca do seu conteúdo, ${ }^{38}$ mas a data da sua realização merece ser assinalada pois antecede a primeira versão francesa (1547) e a primeira versão alemã (1548), só sendo posterior às versōes italianas. Além das traduções, Nunes redigiu também trabalhos em português (e espanhol), como já assinalámos. Esta importante produção de textos em vernáculo, quer traduções, quer textos originais, é, por estes anos, um fenómeno tipicamente ibérico, do qual Nunes se veio assim a tornar um representante de relevo.

${ }^{36}$ Noutro local desenvolvi em maior detalhe este argumento. Vid. Henrique Leitão, «Pedro Nunes against Oronce Fine: Content and context of a refutation", in Alexander Marr (ed.), The Worlds of Oronce Fine: Mathematics, Instruments, and Print in Renaissance France (Donington: Shaun Tyas, 2009), pp. 156-171.

${ }^{37}$ João Fernandes, A Oração Sobre a Fama da Universidade (1548), Prefácio, Introdução, Tradução e Notas de Jorge Alves Osório (Coimbra: Faculdade de Letras da Universidade de Coimbra, Instituto de Estudos Clássicos, 1967), p. 147.

${ }^{38}$ Em particular, não se sabe se seria uma tradução de toda a obra ou, como me parece mais plausível, apenas de alguns dos seus livros (tal como Nunes fizera com a Geografia e as Novas Teóricas dos Planetas), em especial os livros IX e X, isto é os mais "científicos". 
A modo de conclusão destes breves apontamentos sobre a situação de Pedro Nunes no contexto da matemática do século XVI, gostaria de voltar ao que me parece ser o ponto central da sua contribuição para a história da matemática. Já em outras ocasiōes procurei argumentar que ele havia proposto, de forma muito consciente, se bem que não de uma maneira explícita e programática, uma concepção científica muito própria a que, por falta de melhor designação, chamei "programa noniano". ${ }^{39}$ Pedro Nunes propôs e defendeu um programa intelectual que consistia na afirmação de que o estudo da natureza tem de estar fundado na matemática. Apresentou esse programa em especial no caso concreto da navegação, insistindo na dicotomia entre a ars navigandi e a ratio navigandi: a ars, concebida como um saber prático, radicado na experiência e estruturado (nos casos em que essa estruturação se observa) de acordo com os princípios da lógica e da filosofia natural aristotélica; a ratio, isto é, a ciência, concebida como uma metodologia matematizada de interpretação da realidade material. Até Nunes, a náutica e as tarefas da navegação haviam sido concebidas exclusivamente como actividades práticas, como certos ofícios. Nunes alterará radicalmente este entendimento insistindo, primeiro, em que há um navegar "per arte" e um navegar "per razão" e, depois, esclarecendo que a ars navigandi está subordinada à ratio navigandi. Compreender uma certa actividade técnica (como compreender um determinado fenómenos natural) significa para ele compreendê-lo matematicamente.

Para Nunes, a fundamentação matemática de uma disciplina não consiste meramente num tratamento quantitativo. Uma disciplina não se pode considerar matematizada apenas porque alguns resultados vêm expressos de forma numérica. O elemento verdadeiramente crucial é o estabelecimento rigoroso, baseado em provas matemáticas, dos seus fundamentos e o estabelecimento de uma estrutura conceptual que permita a demonstração euclidiana e rigorosa de todos os resultados e técnicas usados nessa disciplina. Fundamentos rigorosos e estrutura euclidiana são a marca das disciplinas verdadeiramente matemáticas. Nas suas mãos as regras empíricas e conhecimentos lentamente acumulados que constituíam a náutica quinhentista são transformados num conjunto de problemas matemáticos; o confuso texto de Alhacen sobre os crepúsculos é transformado num conjunto de proposições matemáticas rigorosamente demonstradas; as consideraçôes semiqualitativas de Aristóteles acerca da questão dos remos são transformadas em cinco proposições matemáticas, encadeadas numa estrutura tipicamente euclidiana; as regras operacionais da álgebra são deduzidas da geometria euclidiana. Até o chamado milagre de Achaz é por ele explicado matematicamente.

Nunes iniciou este programa décadas antes de este assunto se ter tornado num dos eixos mais importantes da "Revolução Científica", e não há dúvida de que o fez com consciência do seu pioneirismo. Este foi possivelmente o seu maior contributo à matemática do século XVI.

\footnotetext{
${ }^{39}$ Henrique Leitão, "Ars e ratio: A náutica e a constituição da ciência moderna", in: María Isabel Vicente Maroto y Mariano Esteban Piñeiro (coords.), La Ciencia y el Mar (Valladolid, 2006), pp. 183-207; Henrique Leitão, "Maritime discoveries and the discovery of Science: Pedro Nunes and Early Modern Science», in: Victor Navarro Brotóns e William Eamon (eds.), Más allá de la Leyenda Negra: España y la Revolución Científica. Beyond the Black Legend: Spain and the Scientific Revolution (Valencia: Instituto de Historia de la Ciencia y Documentación López Piñero, Universitat de València - C.S.I.C., 2007), pp. 89-104.
} 